\title{
The basic competences can be developed through the dual modality in a high vulnerability professional technical license
}

\section{As competências básicas podem ser desenvolvidas através da modalidade dupla em uma licença técnica profissional de alta vulnerabilidade}

\author{
DOI: $10.46932 / \mathrm{sfjdv2n5-048}$
}

Received in: Oct 1st, 2021

Accepted in: Dec 30th, 2021

\author{
José Manuel Salum Tomé \\ $\mathrm{Ph} \mathrm{D}$ \\ Catholic University of Temuco, Chile \\ E-mail:josesalum@gmail.com
}

\begin{abstract}
In the context of Professional Technical Education, Dual Modality has been a commitment of the Chilean Ministry of Education to improve Professional Technical training in High School. The change has involved a curricular innovation around the development of basic competences where, in addition to the teacher and the traditional classroom, other agents and other scenarios that share the work of teaching concur. In this context, the research consigned, according to its objectives and methodological formulation, describes the characteristics of the Dual Professional Technical training of the Administration specialty of the Monseñor Guillermo Carlos Hartl Educational Complex of the Pitrufquén commune, in Chile. It is intended to investigate the effectiveness of the integrated curriculum through the assessment of achievement of the basic competencies of students who are in the 4th Middle Year of said specialty (with Dual mode), in direct relation to the required graduate and professional profile and in contrast, with that of students of the specialty of "Electricity", without the Dual Modality.
\end{abstract}

Keywords : Curriculum design, curriculum, basic skills, didactics, methodology.

\section{RESUMO}

No contexto da Educação Técnica Profissional, a modalidade dual tem sido um compromisso do Ministério da Educação do Chile para melhorar o treinamento Técnico Profissional no Ensino Médio. A mudança envolveu uma inovação curricular em torno do desenvolvimento de competências básicas onde, além do professor e da sala de aula tradicional, concorrem outros agentes e outros cenários que compartilham o trabalho de ensino. Neste contexto, a pesquisa consignada, de acordo com seus objetivos e formulação metodológica, descreve as características da formação Técnica Profissional Dual da especialidade de Administração do Complexo Educativo Monseñor Guillermo Carlos Hartl da comuna de Pitrufquén, no Chile. Pretende-se investigar a eficácia do currículo integrado através da avaliação do alcance das competências básicas dos alunos que estão no $4^{\circ}$ Ano Médio da referida especialidade (com a modalidade Dual), em relação direta com o perfil profissional e de pós-graduação requerido e em contraste, com o dos alunos da especialidade "Eletricidade", sem a modalidade Dual.

Palavras-chave : Desenho curricular, currículo, habilidades básicas, didática, metodologia. 


\section{INTRODUCTION}

The production and socialization of knowledge has become one of the strategic activities in today's society. The growing and sustained influence of science in its reciprocal interaction with technology and the changing rhythm of social demands that impact the world of work, require a transformation of education that allows it to assume new demands for training, learning and socialization (Roca, 2000). Likewise, current trends in the world of work show a high level of competitiveness and increasing qualification standards. All of this requires a complex, multipurpose education and a broad profile of skills to contribute to a better performance of their duties.

Traditional Vocational Technical education has contributed, in a less troubled era than the present, to the training of mid-level professional technicians that undoubtedly improved their job placement opportunities and personal fulfillment. However, the globalization of communications and the market and its incidence in all areas of human life, have evolved towards new paradigms in educational matters, which must address in a more reliable way the training of the individual in function, precisely, of the requirements of today's society, among which are fundamentally those that contribute to increasing human capital in an ever-moving socio-political and economic environment, which requires well-defined capacities to face the challenges of the world of work.

It is known that the education formally is not the only way of learning for one subject, on the contrary, it recognizes the impact of the society in its whole and, above all, of those environments meaningful to the individual as the main areas of learning not formal. In the same way, education is influenced by the context that takes place, given the relationship that is established between educational institutions and communities. Without But this relationship is not given in terms of complementarity, and that the education does not always meet with the expectations of the social environment (what is most evident in relation to the Education Media) but rather well, reproduces the inequalities of the society making one little contribution to the so - called "human capital" so that in economic terms means less productivity and less quantity of goods and services, by thus, fewer opportunities for work .

The demand of the industry production and the employers to the education, and specifically to the EMTP

that the graduates comply with requirements for the exercise professional in conditions and levels suitable as resulting in one rethinking of the design curriculum,

arises then the option of one curriculum for skills characterized by one learning active , centered on the student and mainly oriented to the practical professional. This involves adjusting learning that responds to both theoretical references and empirical work, integrating knowledge from different disciplines, evaluating in a personalized way the mastery of the students' competencies in 
conditions similar to those of the real world, ensuring integration into the curriculum generic or transversal competences, provide the application of knowledge in the real world, among other considerations. It implies also, working in close linkage with the business sector to meet the demand of the industry productive, and establish alliances specific to the process alternated.

All the above poses one setof requirements related to the consistency between the profile exit an $\mathrm{d}$ the objective social of the race, the consistency between the curriculum and the achievement of the profile exit and the forms of assessment curricular preset to verify the achievement of the competencies, a key aspect (the latter) to define strategies that enable comply with the objectives of the implementation of the integrated curriculum.

The need to move towards mobilizing the interests of the population subject to education implies generating spaces for reflection and inquiry regarding the paradigms in use, including the integrated curriculum, the validation of which ultimately depends on the meaning that it acquires for students and their life projects as a means of access to the world of work with real opportunities for insertion, development and personal fulfillment.

The research reported is justified considering that, in order to achieve effective curriculum integration processes, the protagonism of the actors in the evaluation of the system is essential to identify difficulties and formulate solutions, as well as to execute and administer them. On this basis, it is necessary to strengthen both internal and external resources through a dynamic process that accurately identifies the training needs of students, and the spaces that effectively enable it.

\section{NOW, WHAT IS THE PROBLEM WITH THIS STUDY?}

In light of the situation or real problem that has been outlined in the previous lines, it has been considered relevant to take on the challenge of the imperative of improving the training process so that it constitutes a tangible contribution to the dynamics of the teaching-learning process. For this purpose, the integrated competency-based curriculum will be considered in the context of Dual-mode training given at the Monseñor Guillermo Carlos Hartl Educational Complex . From these reasons, the research questions whether the integrated curriculum contributes, indeed, to the achievement of the basic competences of the students of the Professional Technical High Education with Dual training.

The production and socialization of knowledge has become one of the strategic activities in today's society. The growing and sustained influence of science in its reciprocal interaction with technology and the changing rhythm of social demands that impact the world of work, require a transformation of education that allows it to assume new demands for training, learning and socialization (Roca, 2000). Likewise, current trends in the world of work show a high level of competitiveness and increasing 
qualification standards. In addition, the situation is combined with the so-called labor mobility and the recurrent use of information technologies, which requires greater abstraction and skill in the handling of instruments, techniques and machinery. All of this requires a complex, multipurpose education and a broad profile of skills to contribute to a better performance of their duties.

Traditional Vocational Technical education has contributed, in a less troubled era than the present, to the training of mid-level professional technicians that undoubtedly improved their job placement opportunities and personal fulfillment. However, the globalization of communications and the market and its incidence in all areas of human life, have evolved towards new paradigms in educational matters, which must address in a more reliable way the training of the individual in function, precisely, of the requirements of today's society, among which are fundamentally those that contribute to increasing human capital in an ever-moving socio-political and economic environment, which requires well-defined capacities to face the challenges of the world of work.

It is known that formal education is not the only learning path for a subject, on the contrary, the incidence of society as a whole is recognized and, above all, of those environments that are significant for the individual as the main non-learning spaces. formal. In the same way, education is influenced by the context that takes place, given the relationship that is established between educational institutions and communities. However, this relationship does not occur in terms of complementarity, since education does not always meet the expectations of the social environment (which is more evident in relation to Secondary Education) but, rather, reproduces the inequalities of society making a little contribution to the so-called "human capital", which in economic terms means less productivity and less quantity of goods and services, therefore, fewer job opportunities.

The demand of the productive sector and employers towards education, and specifically towards the EMTP, is that graduates comply with requirements for professional practice in adequate conditions and levels, which results in a rethinking of curricular designs, then the option arises of a competencybased curriculum characterized by active learning, centered on the student and mainly oriented to professional practice. This involves adjusting learning that responds to both theoretical references and empirical work, integrating knowledge from different disciplines, evaluating in a personalized way the mastery of the students' competencies in conditions similar to those of the real world, ensuring integration into the curriculum generic or transversal competences, provide the application of knowledge in the real world, among other considerations. It also implies working closely with the business sector to meet the demand of the productive sector, and establish concrete alliances for the alternate process.

All of the above raises a set of requirements related to the consistency between the graduation profile and the social objectives of the career, the consistency between the curriculum and the achievement 
of the graduation profile and the pre-established forms of curricular evaluation to verify the achievement of the competencies, a key aspect (the latter) to define strategies that allow meeting the objectives of the implementation of the integrated curriculum.

In light of the situation or real problem that has been outlined in the previous lines, it has been considered relevant to take on the challenge of the imperative of improving the training process so that it constitutes a tangible contribution to the dynamics of the teaching-learning process. For this purpose, the integrated competency-based curriculum will be considered in the context of Dual-mode training given at the Monseñor Guillermo Carlos Hartl Educational Complex . From these reasons, the research questions whether the integrated curriculum contributes, indeed, to the achievement of the basic competences of the students of the Professional Technical High Education with Dual training.

The proposal presented in this research is based on a performance evaluation of a formative nature aimed at improving the quality of education in Professional Technical High School. It is based on the integration of technical training in a lifelong learning system, in order to raise the quality of academic offerings, increase the enrollment of higher-level technicians and promote technical training based on basic competencies in an integrated curriculum. .

The reality observed is the low achievement of the basic competences of the Professional Technician students in the different specialties generated by the high school. It is for this reason that the Dual Model is introduced in some specialties. One of them is Administration, whose students this training modality seems to have prepared in a better way to face the World of Work with the requirements that they demand.

\section{RESEARCH JUSTIFICATION}

For Monsalve (1999), professional training is a fundamental factor that allows the growth of the person as a worker and as a citizen, since with this he manages to efficiently achieve the objectives of an organization, also contributing to the economic development of the country. In the same way, he points out, the satisfaction of human needs such as self-esteem, security and morale in the worker increases. Generating the conditions for lifelong learning for people is a challenge of a greater order, it is what the country needs to assume to advance in its growth based on sustainable development, integration and progress of people, Concha (2001). This challenge increases every day as a consequence of the changes represented by the already established globalization, which affects all areas of world activity, and particularly the labor market. In Chile, these changes have given rise to a review of the traditional ties that link education with work, in order to effectively strengthen educational systems and respond to the new paradigms of society, particularly the productive world, González ( 2008). 
In a Report prepared for the ILO Inter-Regional Symposium on Strategies to Combat Unemployment and the Marginalization of Young People (1999), it was already indicated that, to solve the problem of unemployment and the consequent poverty, it was necessary to establish Carefully oriented dual learning and education systems, which would contribute to the growth of the formal sector of the economy from an active tripartite participation of the participants of said system (State - Company Student).

Given the country's situation, where the youth unemployment rate has doubled the average rate in the lowest economic strata, it is four times - the GTZ for the first time in Chile, begins to provide its technical cooperation services for the implementation of the Dual Education Program in Chile. It is the same system, with your help, was successfully developed in Germany and is presented as a company owned by the German Federal Government, to work towards the lasting improvement of the living conditions of the population of developing countries and in the process of reforms and to preserve, in this way, the natural bases of existence as expected to happen in our country.

Since 1992, the potential and viability of this model have been experienced in the Chilean reality, introducing the Dual proposal as an alternative for Professional Technical High School Education within the framework of the High School reform, FOPROD (2002).

The essential idea of the Dual proposal for Professional Technical Secondary Education is the introduction of the company in a systematic way together with the theoretical knowledge acquired by the 3rd and 4th year students. It is thus sought that the learning takes place in an integrated and alternate way in the two places. To this end, it is important that the educational offer has a certain relationship with job opportunities and their dynamics in the local / regional environment of the high school or educational establishment.

This modality of Professional Technical Education is defined by FOPROD for the first time in Chile, as a key to bring the world of work closer to the students of technical high schools. However, this does not mean that it is your only goal. So is the continuity of the students' studies at a higher level and the training of people capable of acting autonomously and responsibly in the various areas of life. From this, the design of the curricular framework for Professional Technical Secondary Education emerges, among whose main objectives are:

a) "... satisfy the interests, aptitudes and vocational dispositions of the students, harmonizing their decisions with the requirements of the national culture and the productive and social development of the Country" (MINEDUC 1999) and

b) “... to form an autonomous person, capable of acting competently in real life, social and work situations" (MINEDUC, s / r). 
The consigned research focuses on these foundations, with special attention to the first of them, in order to verify whether the competences acquired by the students of the Dual Mode Administration specialty of the Monseñor Guillermo Carlos Hartl Educational Complex of the Pitrufquén commune, They are effectively those expected from the business sector when hiring a new worker and if, in this way, it satisfies the needs of the company by receiving dual students in its dependencies.

There are several antecedents that characterize traditional vocational technical education in the country. One of them is the difficulty of later integrating into the world of work as well as not having certain abilities that are desirable on the part of the employer, Pérez and Rojas (2001). On the other hand, the trajectory of the students of the Professional Technical Education with dual modality indicates that through teaching with this modality there is a higher level of post-study placement, reaching around 50\% of the graduates, Pérez P, Rojas, C. (2001).

Reflection calls us to think about whether or not this dichotomy regarding the effectiveness of Professional Technical Education is related to the implementation of the integrated curriculum, for which it is essential to know what are the characteristics that constitute Professional Technical Education with Dual Modality that make this modality a better option for the future employment of the students. The opportunity to carry out this study in the same Educational Unit implies that, once the results are obtained, it will be possible to act positively and based on the improvement, not of one, but of both processes for the benefit of the communities that serve the Establishment, aiming at substantive optimization in both cases. In this context, it is considered relevant to approach the problem presented based on the expertise of each of the participating teachers, who together with the students, evaluate the process through the measurement of achievement of the basic competencies considered for this purpose.

The research bases its justification from the initiative of investigating the characteristics, incidence and assessment of the application of the integrated curriculum, as an educational strategy oriented to the achievement of basic skills in secondary education of a Technical Professional character with dual modality. However, from the criteria to evaluate the potential value of this research challenge proposed by Ackoff (1967) and Miller (2002), it is possible to complement the relevance of the study from the following : What is it: Perspectives, Dimensions, Critical Questions?

\section{VIABILITY}

Assuming the viability criterion as the degree of feasibility with respect to carrying out the study on the availability of financial, material and human resources, Rojas (2001) can assert that said conditions and provisions do not in any way hinder the execution of the process. of investigation, mainly due to the 
fact that the universe constitutes the educational community in which the researcher operates due to contractual circumstances.

In conjunction with the above, and given the characteristics of the information gathering techniques (survey, focus group ) and material resources (easily acquired), it does not involve a large economic effort and can be absorbed by the researcher himself.

On the other hand, the social networks and ties that the institution and the researcher (as a director member of the establishment) have with employers in the regional labor market, greatly facilitate the incorporation of these actors into the research initiative, which they access as interested party in the sense of achieving a greater understanding of the training process and its results to which they have been integrated.

Finally, and considering the mainly descriptive scope of the same process, there are no major inconveniences for data collection (fieldwork phase), due to the already described access feasibility and the methodological support of students in practice.

In short, the feasibility of the investigative process is verified taking into account the favorable conditions of the environment under investigation and the excellent availability of the participants and support personnel to said process. In the same sense, this feasibility is expressed with respect to the financial resources involved.

\section{TYPE OF STUDY}

Following the typological classification of research studies carried out by Danhke (1989), it is possible to assert that the research that is carried out has an orientation of descriptive scope, since it aims to investigate the properties, features and characteristics of the phenomenon under study, in In this sense, characterize the teaching processes taught by the Educational Establishment from the Integrated Curriculum and with it the way in which the deployment of basic skills is visualized on the part of the students of the Administration specialty with Dual Modality. Therefore, it allows reflection, complementing about the empirical evidence of certain degrees of association between the application of the integrated curriculum and the development of basic skills, which is assumed as an annex of correlational scope in the same study, which will be defined from the same flexibility and research findings.

Given the mainly descriptive scope that characterizes the consigned research, it is considered pertinent to use a non-experimental design, which makes sense when considering the characteristics of the population, that is, of the students, teachers, teacher guides and actors of the business sector regional, those that are naturally distributed; not being assigned by the researcher and consequently, the 
phenomenon or situation under analysis is not modified; therefore, the results will be relieved according to the gaze and perception of the population according to the attributes that are manifested. Therefore, there is no direct control, handling or manipulation of the variables by the researcher, thus prevailing internal validity.

In view of the above, it is pertinent to specify regarding different methodological moments of the research process, one characterized based on the quantitative methodology, which will focus on measuring the achievement of basic competencies in students of the administration specialty (Dual mode), for what is considered a specific type of instruments with different scales that will allow inquiring about different levels that will structure the operationalization of the defined variables.

On the other hand, and being consistent with the mixed and complementary nature of the investigative process, it will be relieved in a second moment, through qualitative methodology, which, based on an exercise of triangulation of techniques, will allow to complement the descriptive task through the use of " focus groups", through which the different perceptions and evaluations of the different actors involved in the educational process and job placement of the students of the Administration specialty in Dual Mode, belonging to the Technical Professional training of the aforementioned educational establishment

\section{THE DATA COLLECTION PROCESS}

For data collection, two sources of information are used; primary and secondary. Regarding the primary sources, these are those that the researcher obtains directly from the research subjects, through the information collection instruments designed for this purpose.

Secondary sources of information, on the other hand, are written records that also come from a contact with the reality studied, but that have already been chosen and processed by other researchers and / or specialists. For example, those collected from the bibliography, documents, interviews or surveys carried out with previous informants, data and reports from the establishment itself, among others, those that allow the researcher an approach with a preliminary vision of the reality under study.

The primary sources of information are those that have allowed the collection of direct information for research, here we must mention the students of the specialty of administration and electricity, teachers, teacher guides and entrepreneurs, who have provided a valuable supply for research done. It is important to add that the manuals and Dual material that has been issued by the Ministry of Education of Chile have been considered, as support to the high schools for their implementation. It is necessary to highlight that as of today there are no complete studies of the application of this teaching methodology in our country. 


\section{STUDY SAMPLE}

Statistics by themselves make no sense if they are not considered or related within the context with which they are worked. Therefore, it is necessary to understand the concepts of population and sample in order to better understand their meaning in the educational or social research that is carried out.

POPULATION - is the total set of individuals, objects or measures that have some common characteristics observable in a place and at a given time. When carrying out any research, some essential characteristics must be taken into account when selecting the population under study.

\section{Among these we have:}

1 Homogeneity - that all members of the population have the same characteristics according to the variables to be considered in the study or investigation.

2 Time - refers to the period of time where the population of interest would be located. Determine if the study is current or if it is going to study a population of five years ago or if people of different generations are going to be interviewed.

3 Space - refers to the place where the population of interest is located. A study cannot be very comprehensive and due to lack of time and resources it must be limited to a specific area or community.

4 Quantity - refers to the size of the population. The size of the population is extremely important because it determines or affects the size of the sample to be selected, and the lack of resources and time also limits the extension of the population to be investigated.

The entity in charge of the shared financing of the Ministry of Education is the Fundación del Magisterio de la Araucanía, an organism dependent on the Bishopric of Villarrica that was born in 1937, being a non-profit institution domiciled in the commune of Padre las Casas, whose objective is to improve the educational level of children, adolescents and young people in the Araucanía region in light of the evangelizing mission of the Catholic Church, creating educational establishments of basic, secondary and professional technical education, among which the Monseñor Educational Complex is integrated. Guillermo Hartl from the Pitrufquén commune. Although it was born as a Humanist Scientific Lyceum, in 1992 it incorporated the Technical Professional modality, changing its name to the Monseñor Guillermo Hartl Polytechnic Lyceum. Finally it acquires its current name "Monseñor Guillermo Hartl Educational Complex ". 
When conducting a research study, it is generally intended to infer or generalize results from a sample to a population. In particular, a small number of individuals to whom we have access are studied with the idea of being able to generalize the findings to the population from which this sample comes. This inference process is carried out by means of statistical methods based on probability.

The population represents the large set of individuals that we wish to study and is generally inaccessible. It is, in short, a homogeneous group that has certain characteristics.

The sample is the smallest set of individuals (accessible and limited subset of the population on which we carry out the measurements or the experiment with the idea of obtaining generalizable conclusions to the population). The individual is each of the components of the population and the sample. The sample must be representative of the population and by this we mean that any individual from the study population must have had the same probability of being chosen.

What we study in each individual in the sample are the variables (age, sex, weight, height, systolic blood pressure, etc.). The data are the values that the variable takes in each case. What we are going to do is measure, that is, assign values to the variables included in the study. We must also specify the scale of measurement that we will apply to each variable.

The nature of the observations will be of great importance when choosing the most appropriate statistical method to approach your analysis. To this end, we will classify the variables, broadly speaking, into two types of quantitative variables or qualitative variables .

Quantitative variables. They are the variables that can be measured, quantified or expressed numerically. Quantitative variables can be of two types:

1. Continuous quantitative variables, if they allow taking any value within a given numerical range (age, weight, height).

2. Discrete quantitative variables, if they do not admit all intermediate values in a range. They usually take only integer values (number of children, number of births, number of siblings, etc. ).

Qualitative variables. These types of variables represent a quality or attribute that classifies each case in one of several categories. The simplest situation is one in which each case is classified into one of two groups (man / woman, sick / healthy, smoker / non-smoker). They are dichotomous or binary data. As is obvious, on many occasions this type of classification is not enough and a greater number of categories

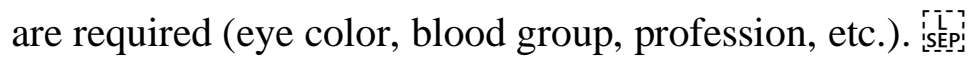

In the process of measuring these variables, two scales can be used:

1. Nominal scales : this is a way of observing or measuring in which the data is adjusted by categories that do not maintain an order relationship with each other (eye color, sex, profession, presence or absence of a risk factor or disease, etc). 
2. Ordinal scales : in the scales used, there is a certain order or hierarchy between the categories (degrees of dyspnea, staging of a tumor, etc. ).

There are different types of sampling. The type of sample selected will depend on the quality and representativeness of the population study.

RANDOM - when selected at random and each member has an equal chance to be included.

STRATIFIED - when it is subdivided into strata or subgroups according to the variables or characteristics to be investigated. Each stratum must correspond proportionally to the population.

SYSTEMATIC - when a standard or criterion is established when selecting the sample. Example: one family will be interviewed for every ten that are detected.

Sampling is essential for the researcher since it is impossible to interview all members of a population due to time, resource and effort problems. When selecting a sample, what is done is to study a part or a subset of the population, but that it is sufficiently representative of it so that it can then be safely generalized from them to the population.

The size of the sample depends on the precision with which the investigator wishes to carry out his study, but as a general rule, a sample as large as possible should be used according to the resources that are available. The larger the sample, the greater the possibility of being more representative of the population.

In experimental research, by its nature and by the need to have control over the variables, small samples are recommended, usually of at least 30 subjects.

Descriptive research uses large samples, and it is sometimes recommended to select 10 to 20 percent of the accessible population.

The reasons for studying samples instead of populations are diverse and among them we can point out:

a Save time. Studying fewer individuals clearly takes less time.

b As a consequence of the previous point, we will save costs.

c Study all patients or people with a certain characteristic in many times it can be an inaccessible or impossible task to perform.

d Increase the quality of the study. With more time and resources available, the observations and measurements made on a small number of individuals can be more exact and plural than if we had to make them on a population.

e The selection of specific samples will allow us to reduce the heterogeneity of a population by indicating the inclusion and / or exclusion criteria. 
_The sample was chosen according to previously established criteria; the research considers 120 students as the subject of the research; from the Monseñor Guillermo Hartl Educational Complex , from the Pitrufquén commune, including 30 teachers, 56 teacher guides (skilled worker) and 60 businessmen, who fit into the participating sample category.

The relevance of the participation of each of the actors involved in this research is described below:

- $\quad$ The research sample is 60 students of the Administration specialty with Dual training of the establishment and 60 students of the electricity specialty without the dual modality, who were chosen for their characteristics of non-traditional training (Dual Training) and traditional training (Training without Dual), which has implied a process of curricular adaptation for their academic training, whose objective is to allow the development of basic competencies through the curriculum integrated to the specialty

- $\quad$ There are 120 students belonging to the sample, from the Monseñor Guillermo Hartl Educational Complex in the Pitrufquén commune, who have been involved in this type of training for one and two years and who are between 16 and 18 years old. They are considered as a sample subject of the research, because they allow to visualize the possible changes that have occurred in their basic competencies during their stay in the company, considering that all have experienced a change in the pedagogical scenario, from a traditional context (classroom) to a real context of work experience (company).

- $\quad$ The 30 teachers of Technical Training, such as those of General Training, are also participants (or participating sample), considering that they must integrate the modules of the specialty with the curriculum of the General Training subsectors.

- $\quad$ On the other hand, the 56 Master Guides are considered, who are in charge of the students during their stay in the company, and must ensure that the Company Performance Plan (curriculum) is fulfilled accompanied by a task rotation plan that allow to achieve the study plan according to decree 220 of the Ministry of Education of Chile.

- $\quad$ Finally, the 60 entrepreneurs are considered to collect information related to the different tasks carried out in their companies and the type of these to adapt the learning performance plan in the company and thus achieve the development of basic skills in the internships of the students during the two years of specialization.

These actors participating in the teaching / learning process of the students are the most appropriate to participate in the research, because by having a connection with the Lyceum for a long time, they provide antecedents from personal and group experience, enriching the collection of information.

\section{INFORMATION COLLECTION INSTRUMENTS}

In order to solve the problem under study, the methods for observing or measuring the research variables should be defined with as much precision as possible. Once the variables have been identified, the exact meaning of each must be clarified. The foregoing was achieved through the operationalization process, through which the theoretical concepts and previously defined variables were translated into more concrete indicators. The measurement of properties or the verification of hypotheses cannot be done at high levels of abstraction, but at levels of concretization that allow their 
identification in reality. It is necessary to select an adequate method to measure them, that is, for the collection of information and data.

As part of the methodological design, it is necessary to determine the method of collecting the information and the type of instrument to be used, for which the objectives and variables of the research study will have to be taken into account.

It is important to affirm that the method represents the way through which the relationship between the researcher and the study participants is established for the collection of data and therefore the achievement of the research objectives.

Some methods used in this research are the interview, direct observation, questionnaire and focus group. The instrument is therefore the mechanism that allows the researcher to collect and record information. The form, that is, if it is about interviews, questionnaires, observations, etc., is determined by the specific techniques chosen; the content, that is, what to ask, what to observe, will be the result of the methodology used.

The methods and instruments to be used depend in each case on the context in which the research is carried out, the committed financial and human resources and the cooperation that is expected to be achieved from the people.

It is necessary to make a distinction between quantitative and qualitative methods. Qualitative ones are usually flexible that allow research subjects to be natural when expressing their ideas. Quantitative methods are structured and controlled, in general they include the use of some formal instrument that allows obtaining the same information from each subject of the investigation. In many studies, these two dimensions of reality are usually combined, although one or the other prevails in a certain case.

The research considers the following instruments, namely:

Standardized closed surveys (Questionnaire): A set of well-structured questions with clear, simple and well-defined language was used. The surveys are applied to the different actors of the Dual system, specifically to those who participate in the teaching-learning process of the Administration specialty that is taught in the Establishment, that is, students, teachers and managers. In this case, the formulation and order of the questions are given to the interviewer, and are conveniently organized into easy-to-use and coding sections.

These instruments were validated, first by experts from GTZ and MINEDUC, then when they were put into practice they were re-validated and restructured according to weaknesses detected by the Dual Rapporteurs of Chile, which served as a pilot with the first dual high schools in Chile.

The structure of the questionnaires includes questions with alternatives such as: $f=$ frequently; $a v=$ sometimes and $n=$ never, or should assign a percentage according to the interviewee's 
appreciation, from 1 to $100 \%$. This structure guarantees a higher degree of reliability and allows a higher degree of comparison in responses. The questionnaires correspond to:

- $\quad$ Students: 2 self-applied questionnaires of inferential appreciation type self-evaluation; The structure of which contemplates the allocation of a percentage according to the achievement achieved by each basic competence (Variables) whose evaluation possibilities range from 1 to $100 \%$ (both included). .

- $\quad$ Students : 1 Self-administered questionnaire type knowledge test, in which the student must carry out the proposed exercise and answer accordingly. This questionnaire contains exercises whose answers have not been structured, but must be developed by the students. This instrument is evaluated with a percentage from 1 to $100 \%$ by the teachers participating in the research, once the students have responded; constitutes a direct evaluation of basic competences in students.

- $\quad$ Guide Teachers : A questionnaire with closed and structured questions, where the participant must answer one of the proposed alternatives. This questionnaire, which includes the evaluation of the students' Performance Areas from the vision of the Guide teacher, is statistically analyzed.

The number of responses corresponds to the total number of interviewees who answered the question (or who evaluated the task corresponding to some area of student performance). That is, if there were 10 interviewees who answered the question, the sum of the results is divided by ten multiplied by two $(10 \times 2)$

It is multiplied by 2 since this is the number that represents $100 \%$ approval of each answer.

- $\quad$ Teachers of general training subsectors and teachers Tutors : A closed structured questionnaire where the participant must assign a percentage according to their appreciation, regarding the achievement of the basic competences of students. And a questionnaire in which they must assign the evaluated task and relate it to the different performance areas to be also evaluated.

This document is validated by its application in various high schools in the country, a situation that allows its application, an instrument also worked by the curriculum and evaluation area of the Chilean Ministry of Education in dual training.

Focus Group : It was used in three large groups, in order to find out what the subjects think and feel about the investigated situation, it was done on two occasions. Through a group meeting of the different actors in the process in order to qualify the results obtained from the applied surveys, endorsing or rejecting them, using the $360^{\circ}$ evaluation model, Alles (2002). It is pertinent to highlight this information gathering technique, differentiating it from Group Interviews, since it maintains various formal aspects, such as, for example, the presence of a moderator and thus a certain time for this activity, which reduces the complexity of your analysis.

Triangulation in research has many advantages because by using different methods in research, they act as filters through which reality is captured selectively. Therefore, it is convenient to collect data from reality with different methods: if the methods differ from each other, they will provide the researcher with a higher degree of low percentage of validity of the instruments, Pérez Serrano (2000). 
Documentary observation: Oriented to gather information on the characteristics of the environment where the students of the specialty of Administration of the establishment operate, analyzed qualitatively- quantitatively. It is integrated into the investigation of summary tables, which are analyzed according to the characteristics of the data.

\section{VALIDITY AND RELIABILITY OF THE INSTRUMENTS}

The instruments used were subjected to content validity criteria, which consists of determining whether the contents of the instrument are sufficiently representative of the dimensions and variables of the study. It is noted that the instruments have been validated by experts from the Ministry of Education through the area of curriculum and its evaluation. Furthermore, it was submitted to the judgment of the Dual national coordination team and the GTZ.

\section{RESEARCH DATA ANALYSIS TECHNIQUES}

The quantitative methodology usually starts from theoretical bodies accepted by the scientific community based on which you formulate hypotheses about expected relationships between the variables that are part of the problem under study. Its verification is done by collecting quantitative information guided by measurable empirical concepts, derived from the theoretical concepts with which the conceptual hypotheses are built.

The analysis of the information collected tends to determine the significance of the predicted relationships between the variables. The procedure is hypothetical-deductive which begins with the formulation of the hypothesis derived from the theory, continues with the collection, processing of data and the interpretation of these. The empirical data form the basis for testing the hypotheses and the theoretical models formulated by the researcher.

It is important to make clear that research with a qualitative approach is instead interested in capturing social reality through the observation of the people who are being studied (students, teachers, teacher guides and businessmen), that is, from of the perception of their own context, Bonilla and Rodríguez (1997).

The researcher induces the properties of the problem to be studied from the way in which he orients and interprets his context that allows him to develop in the reality under examination. It does not start from assumptions, but rather seeks to conceptualize reality based on the behavior, knowledge, attitudes and values that are part of the work of the people studied.

Another important point is that it systematically explores the technical and basic competences shared by individuals in a given work context, Bonilla and Rodríguez (1997). It acts by way of analytical 
induction based on the observation of reality from which the researcher obtains the necessary knowledge to develop the theory that allows him to capture the interpretative schemes of the investigated groups.

\section{QUANTITATIVE ANALYSIS}

An alternative classification of the decision-making process is shown in the following diagram. (according to authors, A., S. and W.)

When using the quantitative approach, the researcher should focus on the milestones or quantitative data associated with the problem and develop expressions that describe the objectives, constraints, and relationships in the problem. Then, using quantitative methods, the researcher must offer recommendations based on the aspects related to the research problem.

The Descriptive Statistical Analysis of the questionnaire is carried out using the excel program. Program for Windows that provides a powerful statistical analysis and data management system in a graphical environment, using descriptive menus and simple dialog boxes that do most of the work.

Once the aforementioned instruments have been applied, the information will be gathered, tabulated, transformed into percentages, analyzed. This will be done using the electronic Excel spreadsheet using the summation and percentage formulas.

The presentation of the results will be made in graphs and contingency table. It should be made clear that the use of the contingency table makes it possible to relate certain variables in descriptive terms, but not to establish statistical correlations or associations, which is not part of the objectives of this study. It is complemented with the information collected through direct observation.

While many users have qualitative method skills, which, moreover, usually increase with experience, quantitative method skills can only be learned by studying the assumptions and methods of management science.

A researcher can increase their decision-making effectiveness by learning more about quantitative terminology and better understanding what its contribution to the decision-making process is.

The investigacdor who knows the procedimeintos of quantitative decision making is in a much better better position to compare and evaluate sources of recommendations for both qualitative and quantitative eventually combine the two sources and make the best possible decision. Quantitative analysis covers most of the material in this investigation. According to the research problem, the appropriate quantitative methodology will be presented and then applied according to needs.

To this, it is feasible to consider some reasons why a quantitative approach is used in the process of decision making when the problem is complex and the researcher does not can reach a good solution 
without the aid of quantitative analysis, as well as The problem to be investigated is very important, it is new in which the researcher lacks experience, and when the problem to be investigated is repetitive and the researcher relies on quantitative procedures to make routine decisions to save time and effort.

\section{QUALITATIVE ANALYSIS}

One of the characteristics of qualitative research is the paradox that although few people are often studied, the amount of information obtained is very large, Álvarez - Gayou (2005). There are multiplicity of sources and forms of data.

There is information that comes from structured or unstructured observations. Another one of interviews, whether open, structured and also less intrusive measures, such as daily or special documents, daily records. In some studies there may be information from questionnaires and surveys, data of various kinds, Miles and Huberman (1994).

It is important to note that qualitative analysis requires a lot of time in research. For example, it takes two to five times more time to process and sort data than it did to collect it (Miles and Huberman, 1994). In addition, the analysis of the information collected is a process that also requires time, it is not done quickly, some authors even consider that it begins before the analysis of quantitative data and that it usually lasts much longer, Álvarez - Gayou (2005).

Once the information has been collected, transcribed and ordered, the first task is to try to make sense of it, Álvarez - Gayou (2005). The great task in this analysis is to simplify and make sense of all the complexity contained in the company visit notes and textual notes, Patton (2002). For this, it is necessary to use coding processes that allow us to develop a manageable classification of codes, Patton (2002).

Now, "interpretation is the lifeblood of whole text analysis", Ryan and Bernard (2003).

Interpretation forces the researcher to make subjective judgments about the meaning of collected text blocks and to make judgments about the meaning of these in the research.

Qualitative data is analyzed and interpreted through intellectual and mechanical work that allows coding the data, finding patterns, and developing category systems. This allows us to analyze the core content of interviews, observations, Focus Group, and other documents that are significant to the investigation. Another important point is that it allows us to determine what is significant for research and from there to recognize patterns in qualitative data and transform patterns into meaningful data, Patton (2002).

In qualitative research, the researcher analyzes and codes the collected data. Data analysis is a dynamic and creative process, with this it is intended to understand more clearly the studied phenomenon and it happens to refine the information obtained. The researcher also relies on his direct experience with 
scenarios, informants and documents to arrive at the meaning of the phenomena starting from the data, Taylor, Bogdan (1998).

Information analysis constitutes a research technique designed to formulate, based on certain data (essentially verbal, symbolic or communicative) inference, reproducible and valid, which can be applied to its context, Hernández, Fernández and Baptista (1998), Bisquerra (2004). For this purpose, interpretive analysis has been considered. However, considering the breadth of the information, you can also use summary tables to facilitate your analysis.

All knowledge construction process requires establishing the methodological criteria based on which it was carried out, therefore this section, as its name indicates, takes up those elements that determine the reliability and validity in the information collection process during the implementation and evaluation of the Technological Literacy Model, specifically the Internet browsing modules and the use of communication tools (See diagram)

Methodological Framework Chart 3

\section{STATISTIC ANALYSIS}

\section{Process:}

- An attempt was made to structure categories that are related to the objectives of the research in order to be able to make comparisons and possible contrasts. The instruments are elaborated according to the information needs that the investigation requires; therefore, it considers the bibliographic review and the creation of questions about its objectives.

- This process is evaluated and its results are presented to the establishment's management and management group, who approve the application of the instrument as a pilot plan and future research.

- $\quad$ The instruments are applied to the entire sample and to the participants, if applicable.

- The table information is emptied

- $\quad$ The quantitative analysis is done.

- $\quad$ The results are presented supported by tables and graphs

- Regarding the qualitative analysis, it is presented in relation to the objectives with which the subject is related.

The data were interpreted by the researcher

\section{Data presentation and analysis:}

The information collected and tabulated is presented in statistical tables in relation to the respective variables and corresponding percentages.

The impact that these responses have on the research topic is analyzed, also presenting general summaries, which will allow to visualize the reality of the quality of performance.

\section{SCENARIO AND CHARACTERISTICS OF THE RESEARCH SUBJECTS}

The entity in charge of the shared financing of the Ministry of Education is the Fundación del Magisterio de la Araucanía, an organism dependent on the Bishopric of Villarrica that was born in 1937, 
being a non-profit institution domiciled in the commune of Padre las Casas, whose objective is to improve the educational level of children, adolescents and young people in the Araucanía region in light of the evangelizing mission of the Catholic Church, creating educational establishments of basic, secondary and professional technical education, among which the Monseñor Educational Complex is integrated. Guillermo Hartl from the Pitrufquén commune . Although it was born as a Humanist Scientific Lyceum, in 1992 it incorporated the Technical Professional modality, changing its name to the Monseñor Guillermo Hartl Polytechnic Lyceum. Finally it acquires its current name "Monseñor Guillermo Hartl Educational Complex ". The Monseñor Guillermo Hartl Educational Complex is located in the commune of Pitrufquén, which was founded in 1897, it is divided in two by highway 5 south and is located south of the IX region of Araucanía, in the province of soldering iron 30Km from Temuco. This commune has an area of $530.7 \mathrm{~km}$ where the limits are as follows to the North is the Toltén river that separates it from the Freire commune; To the south is the commune of Gorbea; To the east it borders Villarrica and to the west are the communes of Toltén and Teodoro Schmidt. The Monseñor Hartl Educational Complex is located on the side of the railway line heading west, surrounded by houses and small warehouses, specifically the territory is rural in nature since the adjoining road is directed towards the countryside, where horses and oxen can be seen circulating through its surroundings, product of the agricultural and livestock trade in the area, it is common to see these types of animals circulating.

Background of the socio-community context in which the educational establishment is located.

The characterization of the socio-community context in which the Educational Establishment is located, allows us to visualize the relevance that Dual Professional Technical education acquires with respect to the educational expectations of the students and the population in general. One of the most important aspects is related to the levels of poverty, access to basic services and the literacy rate, data that account, among others, of the general characteristics of the commune, which presents a lower index of access to education. regional average.

\section{Therefore, as conclusions we can affirm that:}

Although the dynamics of Traditional Professional Technical Education has been implemented in the establishment several years ago, a different appropriation is perceived on the part of the school community -both students, teachers and parents- towards the Dual training modality. In effect, it is shown as an alternative option that generates many more expectations in users and in the educational establishment itself. 
According to the results, the evaluation of the Basic Competences of the students of both specialties consigned in the study, namely, the Electricity specialty of traditional Professional Technical training and the Administration specialty with Dual modality, are dissimilar, presenting averages of approval of the achievement of these far superior competencies in Dual mode students, even in those competencies related to humanistic - scientific knowledge, contrary to what is postulated in the bibliography.

This shows an important differentiation between both modalities. To graph these differences, it is enough to point out that the traditional training students present only one competence - out of a total of eight - with passing achievements above 50 percentage points. On the other hand, the administration students present $100 \%$ of the approved competencies over $50 \%$, and in one of the cases the approval exceeds 80 percentage points (considering the average of all the measurement instruments). These results are equivalent to those found in the qualitative analysis, where businessmen, teachers and students have equal appreciation.

In both experiences, however, there are characteristics of the environment and of the students that make it a difficult task, given the deficiencies that the population has in terms of economic resources and the educational level of the parents and that undoubtedly affect the process. educational as a whole. Another common characteristic is the origin of the students, where $60 \%$ reside in neighboring communes, preferably in rural or semi- rural sectors ; therefore the options of their families (in poverty) are scarce. Therefore, the socio-community context and the characteristics of the students are common to both. On the other hand, the establishment has a team of teachers specialized in Professional Technical Secondary Education, with and without Dual modality, who share the experiences of teaching in both modalities (General Plan).

A first conclusion is that the differences between the two modalities are not in the origin or in the characteristics of the students, nor in the capacity of the high school, but in the curricular modality that each one of the specialties consigned in the study shows, namely, the specialty of Electricity of traditional Professional Technical training and the specialty of Administration with Dual modality.

Among these curricular differences is inscribed, for example, the emphasis on attitudinal and value aspects, as transversal axes of Dual education. In this way, it is understood that an education aimed at promoting social transformation, given the quality of preparing students for the world of work with better placement and hiring options. Even though traditional Vocational Technical training is also oriented towards the world of work, it does not consider the characteristics of the globalized world (the rapid obsolescence of knowledge and labor mobility, for example), which require different skills to successfully 
face the future of work ; while on the other hand it narrows into a closed curricular conception that does not open to the real world.

In Dual mode education, knowledge, skills and concepts are offered by making connections to new ideas and technologies and off-site settings. Their integration is sought so that the student uses the information from their environment in order to acquire genuine learning, where the student learns at their own pace with personalized attention in the context of the company.

On the other hand, and according to what is stated in the theoretical framework and the educational practice itself as a directive teacher, the specialty with traditional modality has little variability in the branches that are not of the specialty, the methodologies do not constitute an incentive for the student .

Consideration of the socioeconomic situation of the students' family acts in two different senses: it acts as a motivating agent since they visualize the possibility of positively transforming their future expectations, which implies a greater demand for technical professional specialties, and that in The case of students with Dual training becomes more attractive from the alternation in the company; Unlike the traditional modality where the projections are more abstract and unstable, given the lack of knowledge of the labor field. However, in another aspect this incidence of the economic situation is negative; since if it is very disadvantageous, it implies an important brake on the development of capacities, even with respect to dual students, especially if the family and the student himself / herself place their expectations on some economic retribution from the company, the that not all offer. In the same framework, it is understood that the deficit situation does not always allow students to attend to tasks in the company with the same spirit and self-esteem as those who have more.

The students who participate in the Dual professional training program, in general, are young people who face early to learn to learn in real scenarios, an environment that requires the student to display values, expressiveness and initiative capacity supporting in the management and production activities, activity that are undoubtedly directly related to how to participate in the processes of quality, productivity and competitiveness in the company.

By making the most of the opportunities offered by the labor market through the LyceumCompany process, young apprentices recognize the role that this company plays in the social, economic and cultural development of the country, since they are all aspects of great importance in the achievement of a better quality of life in people.

In another aspect, coincidentally both in the quantitative and qualitative evaluation, the greatest weakness of the dual education students is verified with respect to digital competence and information processing, which is also felt by teachers and students. that can respond to the organization of the students' 
time, or to a deficiency in the training plan. It is also true that the renewal of IT equipment (for example) is vital in this dual training process, a condition that is difficult to fulfill due to scarce resources.

One of the findings is related to the fact that traditional training students are not better prepared than students with dual skills related to Knowledge Knowledge (scientific humanist areas), even considering that in the curriculum for the traditional modality puts more emphasis on that area than on dual mode. The acquisition of humanistic-scientific knowledge is not conditioned by the modality, but is a deficiency of the entire system and, especially, of all the technical-professional modalities.

The Dual modality allows students to develop all their skills significantly better than traditional training students, in all areas of competence.The evaluation from both models records this fact and shows a better appropriation of all the competences of the students of the dual modality, even though a smaller percentage believe they feel at a disadvantage compared to their peers without dual. This belief is possibly due to the lack of security regarding their own potentialities, or else, ascribing to the general point of view that the appropriation of this knowledge on the part of the dual student is undermined.

Students, in general, feel recognized in the business world as having better qualities than their peers without Dual, therefore, with a better level of achievement in basic skills than their peers with traditional training.

Regarding the characteristics of the learning process in the company, students with dual training know who and what will be evaluated, according to an evaluation Plan already established regarding their training; while students without Dual are evaluated (during the practice in the company) according to the criteria of the evaluator. The above is a comparative advantage for Dual training students, since it translates into a better effort to improve the areas to be evaluated, therefore, with better results; In the same context, there is a relationship of respect for what each one knows and does with respect to the apprentice-company relationship.

The training in the company enables students to learn to adapt their capacities and to make their positions more flexible in relation to the "others", as well as to respond to the technological changes to which the company is subject, a task that is not easy but felt by the actors of the dual system.

The assessment of Know-How not only depends on the student's disposition, but also depends on the learning environment, training and / or the company, in view of the fact that sometimes a worker (or the students themselves) is not appreciated in a company can perform better in another (and be appreciated as such); However, for the student it is essential to have the prior training provided by the educational establishment. But even when the conditions of the work environment are not always the most favorable and their disposition is not appreciated in the right measure, the capacities of the student can break the barriers that prevent their development, which serves as training to face the real world. 
The Master Guide is vital in this process, he is certainly a key piece in Dual training, therefore his choice is of the utmost importance. One of the most relevant aspects is the ability to complement work with teaching, to which they ascribe on behalf of the company and not in a personal capacity.

Dual training students develop better with respect to the complexities of human relationships, both in the educational environment and in the context, a condition given by an emotional maturity that comes from contact and experience in the company and from their own capacity to empathize with the others".

In accordance with the previous observations, a high level of satisfaction of the educational actors (managers, general training teachers, technical teachers, students and business actors) with the process of implementation and development of the Dual Mode is observed. The assessment of the Dual modality by the educational community refers mainly to the achievement of practical learning in students and the acquisition of a work culture that in the Lyceum space is very difficult to achieve and that refers to learning by doing. What is verified, in addition, based on the high demand of students to study specialties with Dual Training, and the number of companies that have assigned to this Modality in the context of the establishment and that have been maintained over time.

\section{SOME SUCCESS FACTORS OF THE DUAL MODEL DETECTED IN THE RESEARCH}

Most coincide in emphasizing that, to achieve the success of the Dual modality during its execution, it is necessary at least:

- $\quad$ Reach a consolidated network of companies as a counterpart. High schools with fewer contacts or networks are those that show the greatest problems or difficulties in sustaining the model.

- $\quad$ Have implemented a vocation induction and assurance system (Vocational Guidance Work Plan) for students prior to the beginning of their Dual training period from the third year of high school.

- $\quad$ Have implemented and consolidated a system for verifying compliance with the Rotation Plan that students must execute in the workplace. The greatest reported difficulty regarding the implementation of Dual Mode.

In relation to the critical nodes, the results, limitations and the evaluation of strengths and weaknesses allow the following questions to be considered as such:

\section{SOME LIMITATIONS DETECTED IN THE RESEARCH}

The present investigation has been limited by different factors attached to the role of the researcher, such as:

- $\quad$ Start of the school year delayed by the catastrophe of February.

- $\quad$ The delay in the signing of learning agreements with companies that are dual centers.

- The late insertion of students to the learning process alternated with the company, due to the late start of the school year.

- $\quad$ The lack of time for entrepreneurs and teachers guides to answer the surveys.

- $\quad$ Lack of Bibliographic material in relation to the Dual Model in Chile.

- Little ability of teachers to work as a team to reach conclusions in the focus group . 
- The difficult coordination of the actors (Students, Teacher Tutor and Teacher Guides) to evaluate the Dual Model.

- The diverse geographical location of the Dual centers (Companies), to apply instruments.

The renewal of student placement positions in companies is also a difficult task, since it requires having sufficient capacity to ensure alternation between companies. It should be noted that Dual training, present in a significant percentage of secondary education establishments in the region, continues to spread, while placements do not satisfy the demand of the system, which could potentially constitute a critical knot Due to the information collected, the Dual coordinators believe that the maximum capacity of companies to incorporate students is being reached, as is the case in some communes, and this limit is also given by seasonality in some specialties, such is the case of agriculture and hotel services, that present a greater increase in non-school periods.

However, the administration specialty maintains its networks for the current enrollment, which does not mean that it covers the demand because the high school has been forced to select students for their insertion to the Project and therefore to the companies.

Finally, it can be indicated that the shortcomings that the FOPROD may present can only be corrected to the extent that their causes are understood, which can be achieved by evaluating the perspective of high schools and dual students. Therefore, it is necessary and necessary to have future research that allows a global vision of the subject to be obtained together.

\section{According to the results obtained in the study carried out, it is suggested:}

- $\quad$ Study how to articulate General Training and Dual Training so that students are not harmed in areas of Basic Training, which implies little preparation to pursue higher studies.

- $\quad$ Seek to apply the Dual model to all specialties, in accordance with real demand.

- $\quad$ Adopt a system of constant evaluation of professional Technical training, so that it serves as feedback and is expressed in substantive improvements for the process.

- $\quad$ Rearticulate those areas in which there is greater weakness,

- $\quad$ Enable a system that enables the establishment's potential business networks to be activated, through cooperation agreements or other means that formalize their membership in the Dual Project.

In sum, the contextualization of the curricular practice is assumed to be highly valued according to the results of the Focus Group, and according to the evaluation of achievement of the basic competences of students of Dual training and traditional training, in which the differences are favorable to Dual training students.

From the point of view of the demands of social coexistence (and not only the demands of the labor market), it is assumed that in the curriculum, in addition to knowledge, a set of competences, knowledge, skills, abilities and capacities are formed of a theoretical-practical order that define the human 
being as a being formed to fully perform in a profession or performance within the society in which they have lived. Understanding the curriculum as the theoretical-practical sociocultural space in which the pedagogical mediation processes are exercised for the integral formation of the student within a specific educational proposal, it is possible to infer that, in the framework of Dual training, the curriculum is It is configured as a new level in which theory and practice come together as a result of the interaction between abstract forms of knowledge and their realization in work practice, at the same time. The competences and knowledge that are achieved from the teaching-learning process of students with Dual training refer to the comprehensive training of students, who are assumed prepared to perform comprehensively.

In this way, the knowledge and knowledge that is achieved in Dual training are closely related to the way in which theory and practice are related, where both experiences are mutually reinforcing for the benefit of the students. In a certain way, there is a certain autonomy of the students to conduct their theoretical and practical training themselves in relation to their personal training. That is, the ability to decide, after critical and self-critical reflection, on the knowledge that must be acquired for its training, based on the concurrence of theory and practice, implies a form of autonomy that allows it to know what it needs to act on the reality in which he has to perform.

Regarding professional Technical training, it is possible to point out that, according to the characteristics, experience and vision of the context under study, Dual training represents the preferential option, not only because the offer becomes more attractive for students, but also because it is they get better results in all respects. This is demonstrated in the measurements of achievement of the competencies of Dual training students, which are compared to the achievement of competencies of traditional training students. In the same way, it is endorsed by the participants of the Focus Group and by the guide teachers who evaluate the performance areas of the students. In general, there is high satisfaction among the actors involved in the Dual training process, where each one feels that they are learning and contributing in a space where society and the private world recognize an efficient and highly effective encounter. 


\section{REFERENCES}

Abarca, N., Hidalgo, C. Interpersonal communication, Social skills training program : Chile Universidad Católica de Chile, 1992.

Acko $\mathrm{f} f$, R. ( 1967). The de sign of social re sea rch . Chicago, IL, USA UU. Universi ty or f Chicago.

Alles, M. Performance by Competence, $360^{\circ}$ Evaluation. Chile: Editorial Granica, 2002.

Arias, M. The methodological triangulation, its principles, scope and limitations . 2009. Retrieved November 19, from the website: http://members.fortunecity.es/robertexto/archivo9/triangul.htm

Arnaz, J. School planning . Mexico, Trillas, 1991.

Astroza , E., Chiguay, S,.., Pérez, Y. \& Rey, P. (2005). Descriptive characterization of the social skills present in children who are in vulnerable situations, specifically in street situations. Temuco, Chile: Catholic University of Temuco, School of Education.

Avila , H. (1996). The urban-rural in the study of territorial processes. Retrieved November 13, 2009 in E. Babbie, Manual for the Practice of Social Research . Bilbao: Desclée de Brouwer Editions .

Baquero, R. (1996). Vigotsky and school learning . Barcelona: Paidós.

Berger, P, Luckmann , T. (1989). The Social Construction of Reality . Buenos Aires: Amorrortu .

Bruner, J. (1997). Education, door of culture . Madrid: Editions Visor.

Caballo, V. (1993). Manual of evaluation and training of social skills. Madrid: Twenty-first Century Editions.

Carretero, M. (1999). Constructivism and Education . Buenos Aires. Editions Aique .

Monsignor Guillermo Hartl Educational Complex (2008). Institutional Educational Project . Pitrufquén, Chile.

Ministry of Education (1997). Support manual for the Student Family Residence Program . Pitrufquen. Chile.

Chiroque Chunga, S. (2004). Curriculum: a tool for the teacher and the student . Buenos Aires: Aique .

Coll , C. Martin, E. Mauri , T., Miras, M., Onrubia , J., Solé, I. and Zabala, A. (1999). Constructivism in the classroom . Barcelona. Graó .

De Zubiría , J. (1994). Treatise on Conceptual Pedagogy . Colombia, Santafé de Bogotá.

Durston, J. (2002). Rural social capital in the management of rural development . Dyads, equipment, bridges and stairs. ECLAC. Santiago de Chile.

Elliott, J. (1994). Action research in education . Madrid, Editorial Morata (2nd ed.) 
Florenciano, R. (2002). Adolescents and their Risk Behaviors . Santiago, Chile: Catholic University of Chile Editions.

Foucault, M. (1969). L'archéologie du savoir . Paris: Editorial Maspero .

FOPROD (2002), DUAL Professional Training, Chile.

Gimeneo , J. and Pérez Gómez, Á. (1997, 1999). Understand and transform teaching (Chapter VI Pages 136-170). Madrid: Editorial Morata.

Gimeno Sacristán, José. (nineteen ninety five). The curriculum, a reflection on practice. Madrid: Morata.

Gonzáles, F., Gutmann, L., Mundana, T \& Muñoz, H. (2005). Meaning of social skills for the various actors of educational institutions in the city of Teтисо. Temuco (Chile): Editions of the Catholic University of Temuco, School of Education.

González, J. (2008). Initial reflections on the conception of curriculum design and development in a contemporary and complex world . Integra Educativa Magazine, 1 (2). La Paz: Plural.

Grundy, S. (1994). Product or praxis of the curriculum . Madrid, Morata Editions.

Hammersley, Marín and Atkinson, P. (1983). Ethnography, Research Methods. Barcelona: Editorial Paidos .

Hernández Sampieri , R. (2006). Research Methodology (Chapters 3, 5 and 6). Mexico : Editorial Mc Graw Hill.

Herrán, A. de la (2012). Curriculum and Renewing Pedagogies in the Ancient Age. REICE. IberoAmerican Journal on Quality, Efficacy and Change in Education, 10 (4), 286-334.

Ibarra, A. (1998). The development of standardized and certification systems for labor competence and the transformation of education and training in Mexico. Paper presented at the Andean Meeting on Training Based on Labor Competence . Bogota

Curricular innovation in Higher Education institutions. ( 1995). Mexico: Editorial Anuis .

National Board of School Aid and Scholarships. Retrieved November 13, 2009 from the website: http://www.junaeb.cl

Kemmis , S. (1998). The Curriculum: beyond the theory of reproduction . Madrid, Editorial Morata, 175 Págs.

Leuca, Y., (2005). The Learning Assessment in a competency curriculum . Lima, IPP Editions.

Lluch, E. (2006). "Introduction to competency-based education". OEI digital library. Workbook No. 2. www.campus-oei.org .

Maldonado, M. (2006). Competences, a life option. Methodology for curriculum design . Colombia: Eco Ediciones. 
Mella, O. (2003). Qualitative Methodology in Social Sciences and Education. Santiago: Editorial Primus Ediciones.

Mendo, J. (2006). "The Curriculum as Social Construction". Rev. Aristas Agosto (1), Lima.

Mendo, J. (2007). "Mediation and Pedagogy". Rev. Aristas August (1), Lima.

Mertens, L. (1997). Labor Competence: Systems, emergence and models . Montevideo: Cinterfor Editions .

Miller, D. C. and N. J. Salkind ( 2002). Handb o ok of re sea rch de sign and social piss your remen t. Thousand Oaks, CA, USA USA: Sage .

Ministry of Education (1998). Chilean Educational Reform, Decree 220 of 1998 . Santiago de Chile: Ministry of Education.

Ministry of Education (2003). Basic studies Ministry of Education . Santiago de Chile: MINEDUCINIDE - Technical Commission of Curriculum (COTEC).

Ministry of Education. Retrieved November 25, 2009 from the website: http://www.mineduc.cl

Nuns, M. (2000). Social Interaction Skills Teaching Program, PEHIS for school-age boys and girls . Madrid: Preschool and Special Education Sciences CEPE.

Monsalve G. Sergio (1999). National University of Colombia Faculty of Sciences, Santafé de Bogotá.

Morín, E. (2000). The seven necessary knowledge for the education of the future . Colombia. Ministry of National Education. Pp. 1-75, Ediciones Morata, (3rd edition)

Muñoz, J. (1998). Implementation of a selection system by competencies . Traning and Development Digest . Editions University of Deusto.

Musitu, G. (2000). Family socialization and values in adolescents: an intercultural analysis, vol.31, no 2, 15-32.

ILO. (1993). Vocational training. Glossary of chosen terms . Geneva: Cintefor Editions .

Olivares, L. (2005). Rural or Urban? Approach to the type of identity existing among the inhabitants of the rural-urban sector of Pérez Ossa, Commune of San Bernardo. Thesis to qualify for the Title of Social Anthropologist. University of Chile, Santiago, Chile.

Ornelas, C. (1995). The Mexican educational system. The end of the century transition. Economic Research and Teaching Center - Nafinsa - Fondo de Cultura Económica. Mexico. pp. 1-55

Ortiz Cabanillas, P. (2003). The formation of the personality . Lima, Editorial Orión.

Palacios, J. (1989). Parents' ideas about their children's education. Seville: Institute of Regional Development.

Papalia , D. (2001). Developmental Psychology, Vol II . Bogotá: McGraw- hill Interamericana Editions . 
Pedró and Puig. (1999). Educational reforms: A political and comparative perspective . Barcelona: Paidós Editions.

Peñaloza Ramella , W. (2000). The comprehensive curriculum . Lima, Ediciones Optimize.

Pérez M. Paulina, Rojas A Claudia (2001). Proposals for improvement for the dual vocational training system. Thesis. University of Santiago de Chile, Department of Industrial Engineering.

Pérez Serrano, G. (2000). Qualitative Research Methodology, Volume II Techniques and Data Analysis . Madrid: Editorial La muralla, 3rd edition.

Perrenoud , P. (1999). Build skills from school . Santiago de Chile. Dolmen Publishing House.

Ponce, E. (2012). Education and class struggle. La Habana, Ed. People and Education.

Roca, Enrique. (2000). The early abandonment of education and training in Spain. Education Magazine, ISSN 0034-8082.

Sacristán, J. (1999). The Curriculum: Teaching Contents or an Analysis of Practice ? Madrid: Editorial Morata.

Salgado, H. (2004). Curricular theory and doctrine . Peru: Editorial San Marcos.

Sandoval, C. (2002). Qualitative Research . Colombia: Arfo Editions.

Santrock, J. (2004). Developmental psychology in adolescence . Madrid: Mc Graw-Hill Editions.

Stenhouse, L. (1993). Research and development of the curriculum . Madrid: Editorial Morata.

Taba, H. (1976). Elaboration of the Curriculum. Theory and Practice . Argentina: Editorial Troquel.

Taylor, M. (1998). Competency-based education and training: an overview of the UK experience . In: Training based on job competence . Cinterfor / ILO, POLFORM / ILO, KNOW. Tools for transformation series . Cinterfor / ILO.

Taylor, SJ, Bogdan, R. (1998). Introduction to qualitative research methods . Barcelona: Editorial Paidós.

Tobón, S. (2005). Competency-Based Training. Complex thinking, curricular and didactic design . Colombia: Ediciones Eco.

Torres, J. (1998). Globalization and interdisciplinarity: the integrated curriculum . Madrid: Morata Editions.

Vigtsky , L. (1998). The development of higher psychological processes . Mexico. Review.

Vygotski , Lev S. (1995). Selected Works . Madrid: Ediciones Visor, T.III.

Wolfgang, K. (1993). Curriculum and general Didactics . Quito: Abya-Yala Editions . 